\title{
Design and Implementation of Mobile Game System for Vitalization of Culture Tourism
}

\author{
Sungwook Yoon and ${ }^{l}$ Hyenki Kim ${ }^{1, \text { Corresponding Author }}$ \\ Dept. of Multimedia Engineering, Andong National University, \\ 388 Seongcheon-Dong, Andong-City, Gyeongsangbuk-Do, Republic of Korea \\ uvgotmail@nate.com,hkkim@anu.ac.kr Corresponding Author
}

\begin{abstract}
The travel pattern is changing to provision of personal customized information through the mobile based tourism service due to distribution of Smart devices. Easy acquisition of the tourism information through mobile devices changes the existing tourism based on looking around to approaching the in-depth tourism information and the type of information also changes to various types such as game or mission carry-out from the simple information. This paper studied the methods to experience and acquire the educational tourism information through not only the provision of the simple information through the location based service of the tourist sites but also carrying out the mission using the location based sensors, Question typed game, joint solution and competing solution and designed and implemented a mobile game system to vitalize the culture tourism.
\end{abstract}

Keywords: Mobile, Game, Culture, Tourism, LBS

\section{Introduction}

A change in behavior to consume the information of the recent mobile based tourism service and travel patterns is getting accelerated according to distribution of the mobile devices. The essential lists such as the existing maps and guide book could be acquired wherever and whenever due to development of the communication and media that the patterns for the travel of the tourism consumers is changing. The information exchange for the travel or tourism is made horizontally between the tourists and the PR for the tourist sites by the local government has been changed significantly that it recognizes the mobile as a big area of PR. The distribution rate of mobile devices in Korea exceeds two times of the whole economic population as of 2014 and now, the tourism infrastructure of Korea has an environment to contain the information sufficiently since the tourists may seek for the contents desired through the mobile devices due to development and convergence of the communication and media technologies. An active implementation of the ubiquitous mobile consumption makes the contents of the convergence between the communication and media technologies using the mobile device [1].

The development of infrastructure for the tourism information itself is not relatively well established in terms of utilization while the technology and trend of the information communication are newly developed every day and the tourism consumption by the tourists is active [2]. Namely, not only the technical environment to provide the tourism information but also various models for providing methods based on the user are required. It needs to provide the Smart information suitable to the personal users, tourism experience and in-depth information of the hidden side and induce the consumption of more active culture tourism by establishing a database of the user's tourism information consumption[3]. 
This research has implemented a program for participating model to consume the tourism information of location base and mission carry-out type utilizing the Smart devices of the tourists in terms of active acquisition of culture tourism.

\section{Related Researches}

LBS (Location Based Service) is a service which provides the improvement of the work productivity and various life conveniences utilizing the location information and now is highly leveled by combining the user information, augmented reality and social network to the location information utilizing Smart Phone, a personal mobile information device.

GIS (Geographic Information System) for government agencies such as B2B(Business-to-Business) and G2G(Government-to-Government) become an axis of the business model in certain industries through LBS and other LBS, such as B2C(Businessto-Customer) or G2C (Government-to-Customer) mediating the personal mobile devices are now modeled for personal service (Figure 1)[4].

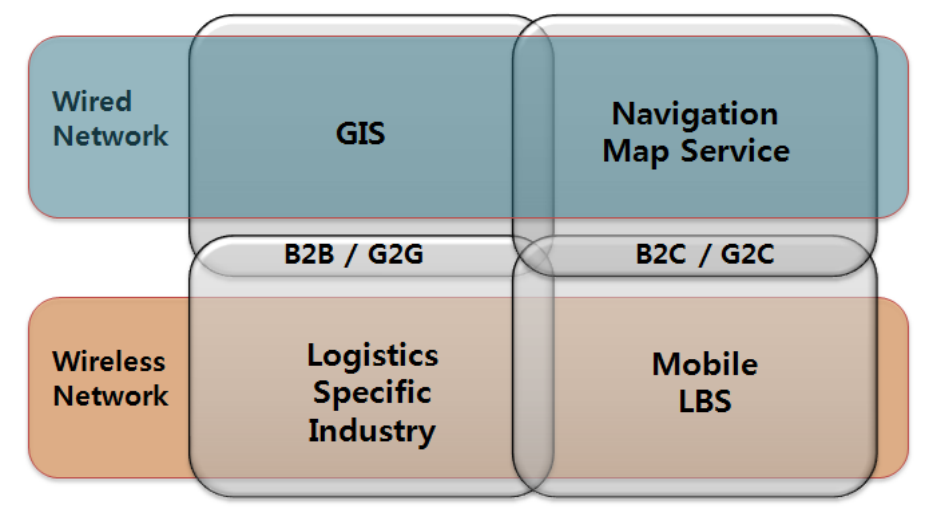

Figure 1. Location based Service Types

Many off-line enterprises are actively react in order to utilize the LBS functions in mobile e-commerce in the service innovation cases. For the regional stores like restaurants, cafe, beauty salon, theatre and private academy, the mobile advertisement service which offers the discount coupons based on the location information is expected to be an effective promotion means. In addition, the LBS connected with social network are appearing since forming the mutual intimate relation and sense of fellowship between the customers are favorable for the business of the regional store.

LBS has been started when GPS(Global Positioning System) was established in 1970's and recently, the technologies utilizing Wi-Fi network and sensor network are appearing.

LBS has been highly leveled (LBS 2.0) by combining the user information, augmented reality and social network to the location information utilizing Smart Phone, a personal mobile information device that they may understand the location in any place whether indoor or outdoor utilizing both GPS and WiFi network together and express the results together with camera images as well as on the map. It is easy to provide the personal customized service utilizing the information about the behaviors and favorites of the user and utilize the social network actively in terms of acquisition and utilization of the information.

The services utilizing LBS are widely used in distribution, neighborhood living service, transaction tourism service and public service sector of the local government. Especially, it enhances the profitability providing the differentiated personal customized travel service combining the location information and user information in relation to 
tourism and now the Place centered travel service is being evolved to Travel 2.0 Service which is People centered service reflecting the favorites of the personal traveler.

Meantime, KTO provides and opens the tourism related information by Open API that they could be provided with the selective information through the necessary tags. Provision of Open API enables the joint activity of the information resources that various information services could be implemented by connecting and converging the external resources to the limited resources and they may save the cost and time for developing the information service since they use the resources already opened. It has the merits to create the new service granting the new value and naturally establish the monitoring system for quality control of the data in terms of providing the information.

It is possible to utilize the basic public data and save the cost and time for development using the Mash-Up technology by parsing processing of RSS(Rich Site Summary) and XML (eXtensible Markup Language) through Open API [5-6].

\section{Design and Implementation of Smart Tourism System}

Open API is freely available for an personal or institution who acquired the right to use Open API through the national knowledge portal search service which is under service based on the national knowledge established through connection with national knowledge provision agencies [7].

KTO also provides various tourism information through Open API and such information is provided in form of XML and could be read by RSS. The data delivered by XML may express the information necessary for the user parsing the result value after organizing and acquiring the prescribed necessary tag.

Table 1 shows TourAPI which is Open API provided as public data, provided with necessary API Key and shall be processed after being parsed based on the necessary tag. TourAPI provides the overall tourism information by region and My position received from the public data services of national agencies such as KTO and Korea Meteorological Administration ("KMA").

Table 1. Open API that is Provided as Public Data

\begin{tabular}{|c|c|c|}
\hline Open API & Contents & Oragniztion \\
\hline $\begin{array}{l}\text { Regional tourism } \\
\text { information }\end{array}$ & $\begin{array}{l}\text { By providing the tourist information of each sphere area, } \\
\text { and maintains a general tourist guide DB, it is easy to } \\
\text { search the user according to categories. }\end{array}$ & KTO \\
\hline Nearby Attractions & $\begin{array}{l}\text { Location based and it will be possible to search the local } \\
\text { attractions and events. }\end{array}$ & KTO \\
\hline Advanced Search & All constructed DB can be retrieved based on the query. & KTO \\
\hline Event Date Search & $\begin{array}{l}\text { It is possible to date another search of community events } \\
\text { and their event. }\end{array}$ & KTO \\
\hline $\begin{array}{l}\text { Accommodation } \\
\text { Search }\end{array}$ & $\begin{array}{l}\text { Accommodation search of the nearby attractions are } \\
\text { possible. }\end{array}$ & KTO \\
\hline Weather data RSS & Provision of meteorological data & KMA, Internet portal \\
\hline
\end{tabular}

The user sets his/her present position or tourist site position and personalize the information in accordance with the setting. The personalized data is designed to push or inquire the message in Smart device.

A server including Open API of KTO is organized in order to be provided with the real time information through the tag after selecting the necessary tag by producing the public 
data in form of XML. The server was processed by parsing based on Javascript using the external API necessary for providing the tourism information. The parsed data shall be provided after reading the mission carry-out environment and GPS information using the prescribed user's log information DB. Figure 2 shows the parsing and processing process of such data.

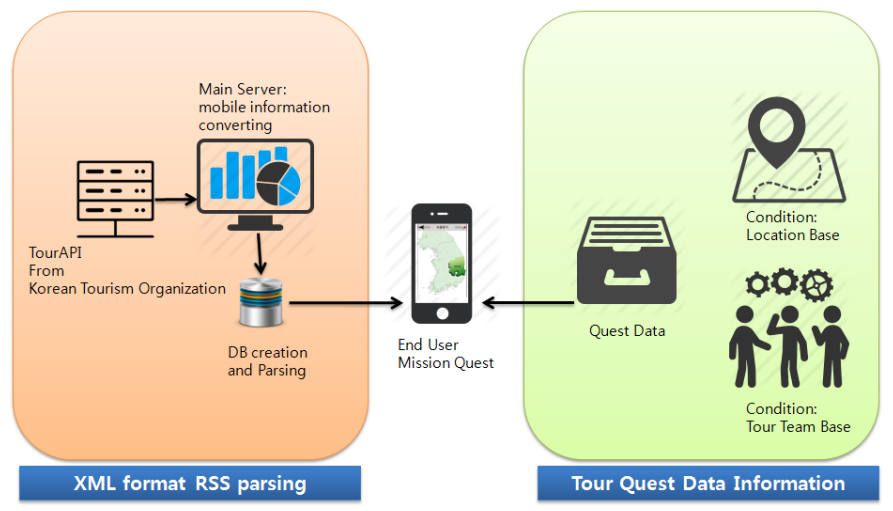

Figure 2. Parsing and Processing Process of Data

Through this, the integrated mobile application has been consisted of Target Tourist Site Guide Page, Mission Carry-out Page, Organizing the Expedition by Team and History Administration which ministers the personal performance.

For the basic tourism information, the detailed tourism information was provided referring the regional tourism information and the location based data was extracted processing the village weather forecast of KMA for daily weather information. The methods to develop and provide the objects and issue of the tourists site have been organized based on LBS information of mission carry-out and provided the services such as single answer of webtoon(Webcomics also known as online comics or Internet comics[10]) instruction typed Quest carry-out and location based arrival mission etc.

The database implemented with its own system is schematized in order to create the Quest data analyzing the information of each tourist sites and submit the LBS Questions. Below figure Figure 3 shows the relation between the application activity modules of the Quests implemented as each Open API and database.

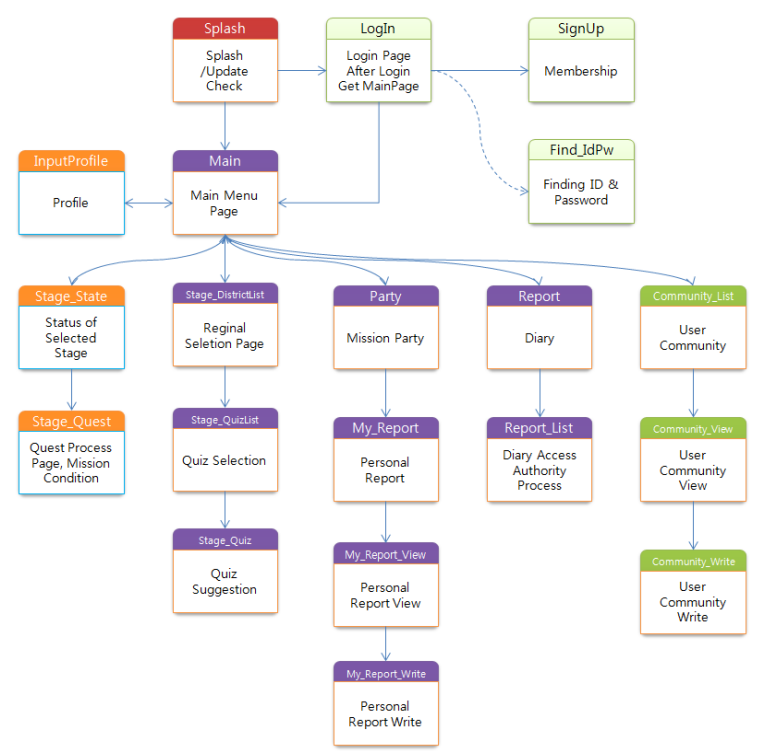

Figure 3. Activity Module Structure of Database to be Implemented 
The application is designed so that acquiring the information becomes easy and cowork and team formation of mission carry-out through connection with tourists are available by delivering the personalized information through the tourism information and weather information of the tourist sites to Smart devices and identifying the related policies, education and tourism points.

Table 2. Definition of Functions of Culture Tourism Vitalization Application

\begin{tabular}{c|l}
\hline Item & \multicolumn{1}{c}{ Contents of the function } \\
\hline $\begin{array}{c}\text { Guidance of } \\
\text { destinations }\end{array}$ & $\begin{array}{l}\text { Select tourist attractions and provide location-based data on local history and tourist } \\
\text { information in the form of cartoons }\end{array}$ \\
\hline Treasure Hunt & $\begin{array}{l}\text { Function of storing the hidden information in the DB and Destinations individually } \\
\text { perform mission-form or in the form of a problem based on the arrival position }\end{array}$ \\
\hline $\begin{array}{c}\text { Expedition } \\
\text { configuration }\end{array}$ & $\begin{array}{l}\text { Quest for the expedition accomplished by configuring the individual or entity to } \\
\text { perform the following objectives to participate in individual quests majority }\end{array}$ \\
\hline History management & $\begin{array}{l}\text { Manage and administer the results of individual historical attractions quest done in } \\
\text { accordance with the objectives to DB }\end{array}$ \\
\hline
\end{tabular}

Below Figure 4 summarizes the mission carry-out according to each function and its order of the application, Quest carry-out and procedure to acquire the points. It is designed so that each intended purpose strengthens the connection each other and each element shall achieve the common purpose adding the planning by each procedure in order to attract the interest and learn the effective tourism information.

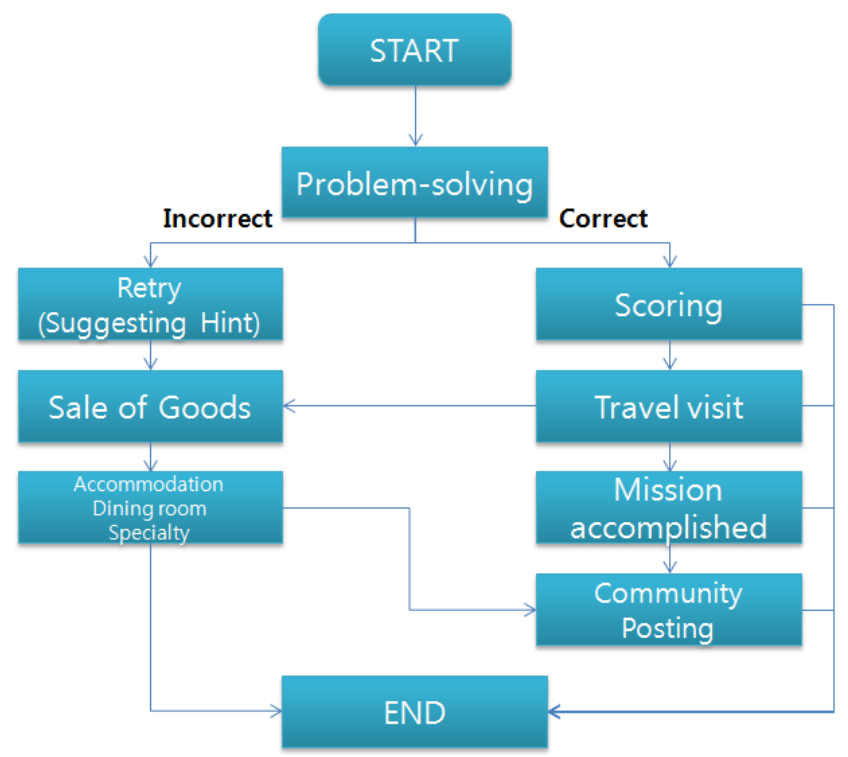

Figure 4. Perform Functional Content of the Program

Figure 5 shows the diagram which provides the personalized custom data mixing each Open API information. The procedure to provide the real time information of the system server through the mobile and mobile terminal are shown on Figure 5. 


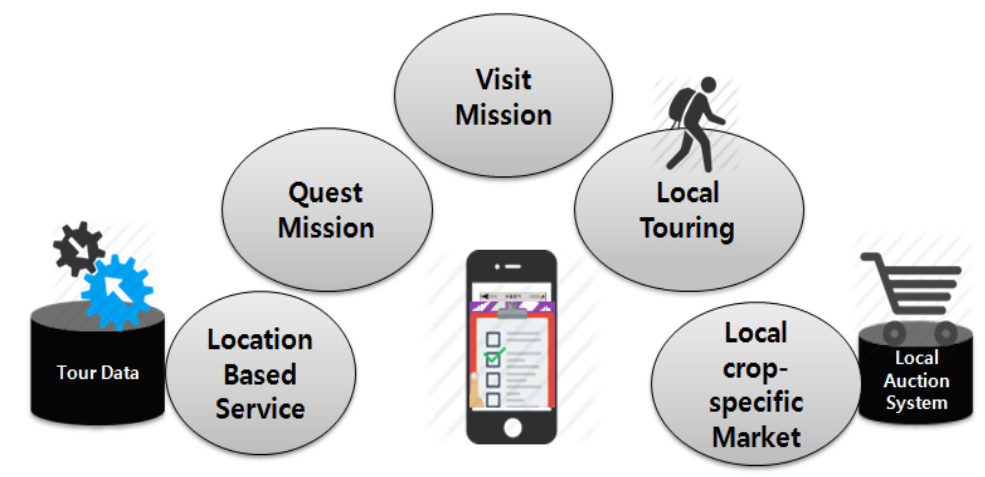

\section{Figure 5. Diagram to Provide Personalized Custom Data by Combining Open API Information of Each Party}

The application induces the acquisition of the points through traveling the region or tourist sites based on the visit mission and Quest mission carry-out and stores the public RSS data and the basic traveling information of KTO's Open API data in unprocessed form (1). The user's area shall receive the location information from terminal's GPS and base (2) and reQuests the mobile application to service the tourism information, weather information and tourism mission Quest established in its own system to the server (3) and transmit the data in Question to Smart Phone after processing in the server (4).

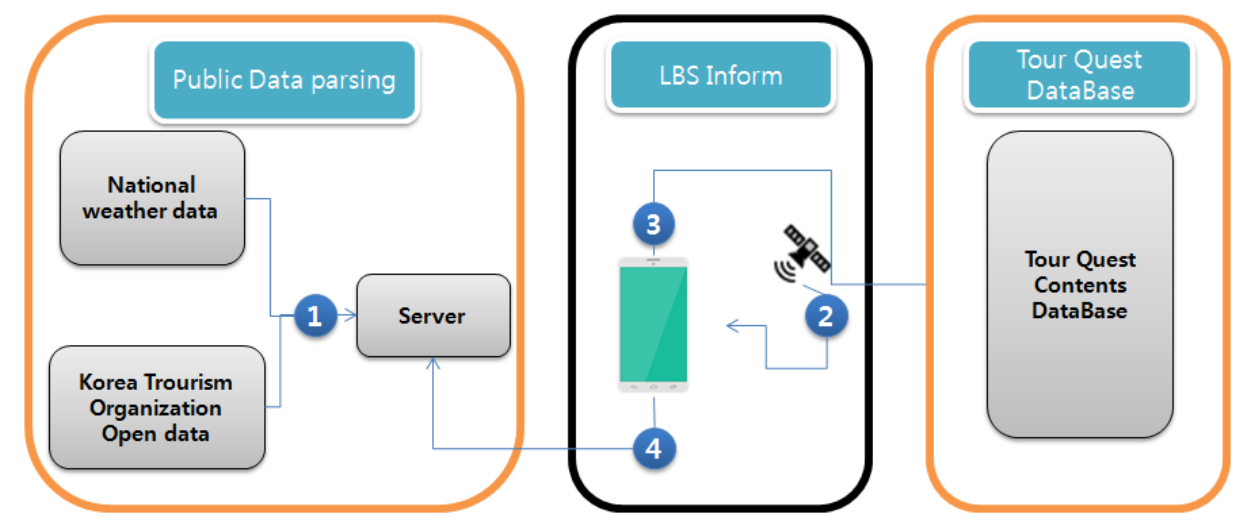

Figure 6. System Structure Diagram to Provide Tour Information and Tour Quest DB

The application implemented includes Target Tourist Site Guide Page, Treasure Hunt, Organizing the Expedition and Administration of Exploration History etc.

Java SE 7 u45 version SDK of Oracle.com was used as a basic using Android 2.2 (Froyo) 4.4 (Jellybean) platforms of Google and Eclipse Standard 4.3.1 of eclipse.org was used as an official tool in development of this application. In this case, Android Virtual Device (AVD) provided by the platform was used as the tool for Table Test and the tools of Field Test were tested utilizing various Smart devices (Smart Phone and Tablet). Figure 7 shows the capture screen of the application implemented. 

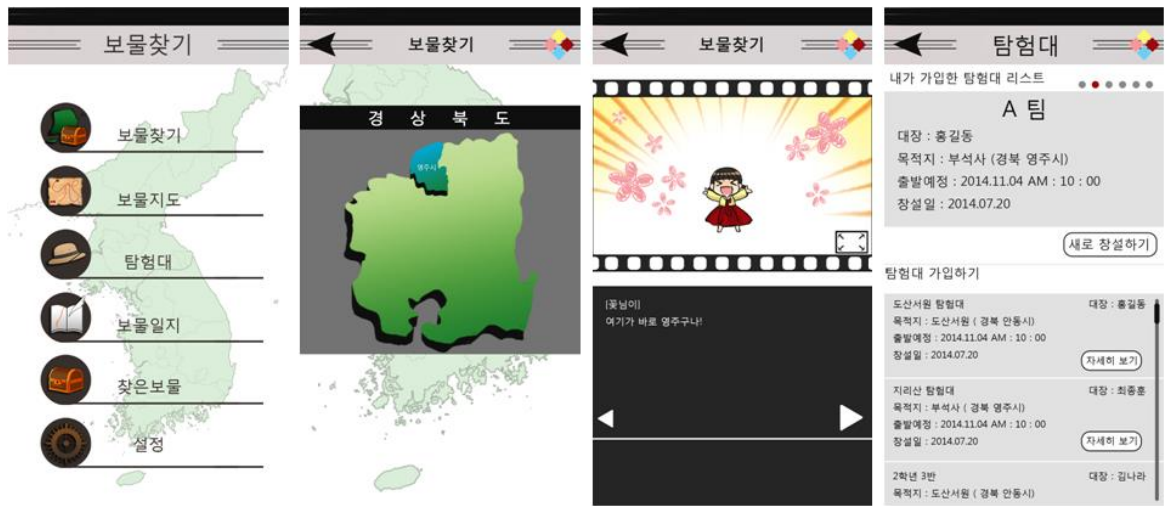

Figure 7. Screen Capture of the Application

Specific locations and user's positions are indicated in the map using Google Maps Android API v2 and the service according to the present position is also indicated using GPS coordinate value.

\section{Conclusion and Future Research}

Tourists may provide and acquire the information through mobile at any time and place and easily acquire the information of the tourist sites using the location based sensor function of Smart Phone. Through this, not only the acquisition of the tourism contents but also the customized information for the tourist such as the food, accommodation, special products and other general stuffs is available connecting with the commercial area of the tourist sites. Through this, the sales increase of small business and local economic vitalization could be brought and further the development of App contents for exchanging the information between such small business is required. An effective platform which may exchange the live information of the users forming the community for Apps and culture tourism, strengthen the relation by preparing a place to exchange the information such as UCC and bulletin board, and secure the high loyalty customers in culture tourism sector is required.

A game system to vitalize the culture tourism has been studied and implemented based on the contents suggested in this paper. This system is designed to experience the more active tourism culture by operating the database which may establish the personal participation model in the tourism industry sector through active utilization of personal Smart devices. Recognizing the necessity of the local government to manage and publicize the regional culture together with location based functions such as GPS, the information system to quantify the active culture experience and consumption pattern was designed and implemented.

Considering the recent culture consumption trend, this paper is expected to deliver the tourism contents and humanistic elements effectively to the tourists by studying or carrying out the mission instead of just look-around tourism. This, further could be utilized as one of the methods to publicize the cultural location and vitalize the economy.

\section{Acknowledgements}

This work was supported by a grant from 2014 Joint-industry-academic Research Fund of SMBA, Korea. 


\section{References}

\subsection{Book}

[1] W.-S. Sim, "Recent changes in tourism trends and future policy direction", Korea Culture \& Tourism Institute (2010).

\subsection{Chapter in a Book}

[2] Mobile Services and Tourism: From Tourist Information to its policy, Convergence Lab Policy Statistics Center (2013).

\subsection{Journal Article}

[3] S. Alshattnawi, "Building Mobile Tourist Guide Applications using Different Development Mobile Platforms", International Journal of Advanced Science and Technology (2013), pp.1322.

\subsection{Journal Article}

[4] K.-K. Seo, “An Explorative Model for B2B Cloud Service Adoption in Korea - Focusing on IaaS Adoption”, International Journal of Smart Home (2013), pp. 155-164.

\subsection{Journal Article}

[5] S. Shahriar and J. Liu, "Updating in XML Using Semantic Constraints", International Journal of Database Theory and Application (2011), pp. 1-12.

\subsection{Journal Article}

[6] Han, S.-H. Ryu, D.-Y. Lim and Young-Hwan, "A Personalized Mobile Service Method of RSS News Channel Contents for Ubiquitous Environment", The KIPS Transactions, Korea Information Processing Society (2007), vol. 14D, no. 4, pp. 427-434.

\subsection{Journal Article}

[7] Y.-s. Kim, "A Study on Legal Issues of Public Data Management as Records: Focused on Analysis of the Act on Provision and Use of Public Data", Records Management Society of Korea (2014), vol. 14, no. 1, pp. 53-73.

\section{Authors}

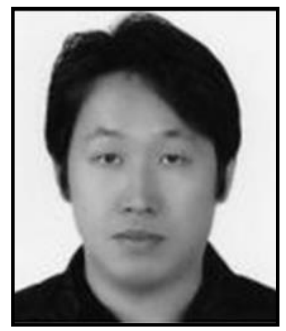

Sungwook Yoon, He is studying Doctor course in multimedia engineering from Andong National University, Korea. His research interests include multimedia contents, e-book and Internet of Things.

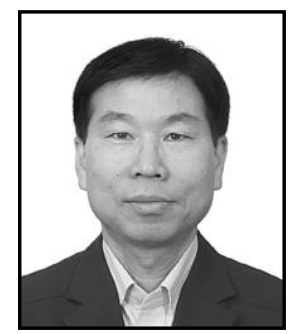

Hyenki Kim, He received the B.S. and M.S. degree in electronics engineering from Kyungpook National University, Korea, 1986 and 1988 respectively. He received $\mathrm{Ph}$. D. in electronics engineering from Kyungpook National University, Korea, 2000. He joined Andong National University in 2002, where he is currently a professor at Dept. of multimedia engineering in Korea. His research interests include multimedia system, mobile app. and Multimedia communication 